\title{
A Case for Introducing Applied Psychology in the Management School in Pakistan in Research Degree Programmes with Emphasis on M Phil Programme
}

\author{
T. Shakoor and A. Yameen
}

\begin{abstract}
The study highlights Psychology's roles in Management Sciences and the usefulness of its application for better managerial skills for the students. The research uses the desk study method based on reviewing the secondary data on management sciences, behavior and culture, applied psychology, personality development, organizational and industrial psychology and organizational behavior to make a case for introducing Psychology in its applied form as a course in the Management schools in Pakistan at the tertiary level with a especial case scenario for the M Phil in Management Sciences. Application of subfields of Applied Psychology will help understand the organizational environment, work-based interactions, organizational control and decision-making. Psychology can be used in employee selection, employee motivation, employee satisfaction, and productivity, training, development, evaluation and understanding work-based environment. Psychoanalysis, behaviorism and humanistic psychology can be a useful study for consumer behavior for marketing decisions, studying consumer buying behavior, exploring impulse buying, product customization and product preference. The research achieves its value by thoroughly studying the literature on the application of psychology in management and industry to establish the importance of making psychology a permanent course in $M$ Phil programmes in Pakistan at the management schools.
\end{abstract}

Index Terms-Leadership, psychology, management school, managers.

\section{INTRODUCTION}

"It is too often assumed that almost any young university graduate of sufficient intelligence can charge out of university and into industry and, armed with some rags and tatters of scientific method borrowed mainly from physics or chemistry, can proceed to make interesting findings. This belief ignores completely the mutual dependence and complexity of the facts of human association."

Elton Mayo (Smither, The Psychology of work, 1994) [1] Management school generally has focused extensively on creating managers with technical and work based skills. Their view is wholly concentrated on the work mechanisms and how to mine results out of employees in order to maximize profitability for the organization in which the managers are working. Even though researches and studies have shown that classical management theories have rendered results both positive and negative for the employees the view that management required only to work and ensure that

Manuscript received March 9, 2017; revised May 15, 2017.

T. Shakoor is with the Bahria University, Pakistan (e-mail: toobashakoor@hotmail.com). organizational apparatuses prove financially sound for their organizations, this view however is very restricted. The postindustrial world necessitates a lot more for the organization in terms of understanding of employee behavior than what has previously been understood and practiced. The focus of this concept paper is to show the significance of introducing applied psychology not just with it industrial, organizational, psychoanalytical and behavioral aspects but also incorporating the humanistic domain in it.

The case argues that managers first need to be seen as humans with a mental makeup which maybe too intricate to understand and controlled through management theories alone. Students of management need to understand the psychology behind behavior whether exhibited by consumers, employees, administration, CEOs or organizations being run by humans developing psychology of their own. Therefore it is important for the students of management sciences to be well read on theories of psychology and psychology as a science to know how humans working in different capacity within the organization work. The idea is not to produce psychiatrist deeply involved in studying behavior and applying remedial treatments but to introduce tolerance for deviation from normal behavior and an understanding of what may be the causes behind such behavior and its organizational ramifications. To do this it is required that the study first establishes the conventional and predominantly perceived and empirically proven roles of managers in the organization and industry through the literature review.

\section{OBJECTIVE}

The objective of the study is to highlight the role psychology plays in various branches of management sciences and how the know- how of the practical application of psychology in its various modification can help students of management become better managers. In other words it elucidates how psychology can help mangers make better decisions especially those concerning co-workers, subordinates and superiors. Therefore the study builds a case for introducing psychology as a permanent feature in the curriculum at the tertiary level education in Pakistan with special emphasis on M Phil programme.

\section{TERTIARY LEVEL EDUCATION IN PAKISTAN}

"Today, more than ever before in human history, the Wealth -or poverty- of nations depends on the quality of 
higher education. Those with a larger repertoire of skills and a greater capacity for learning can look forward to lifetimes of unprecedented economic fulfillment. But in the coming decades the poorly educated face little better than the dreary prospects of lives of quiet desperation".

Malcolm Gillis, President of Rice University, 12 February 1999 (Sam, 2016) [2]

Education in Pakistan is divided into public and private sector. Higher education comes under the umbrella of an autonomous body, Higher Education Commission (HEC), responsible for policy formulation, funding and improving the quality of output of higher education institutions and the alignment of these institutions with the job market. HEC was established in 2002. It replaced the University Grants Commission previously responsible, under the federal government, for tertiary level education in the country. There are 203 fully functional Universities working under HEC (www.hec.gov.pk). In 2005 the student enrolment in HEC recognized universities was about $2.6 \%$. HEC's goal is to push the number to $8 \%$ by 2020 HEC was established to ensure that the unprecedented increase in the number of universities due to a high demand of tertiary education in Pakistan with little or no attention given to the quality of instruction, the university infra-structure and curriculum planning is curtailed. HEC has a strict criterion for quality assurance which the Universities need to ensure that they follow in order to maintain their recognition by the Commission. The federal criteria for private sector Universities have classified the universities on four broad delineations mainly academic, financial, physical and infrastructural. The universities lose their recognition failing to maintain HEC requirements (Nordic Recognition Information Centres, 2006).

M Phil in Pakistan is a two -year research based degree programme which includes both course work and research thesis. The research students have to complete a minimum of 24 credit hours as per HEC requirement and 06 credit hours are allocated to research thesis (www.hec.gov.pk). HEC revises its curriculum from time to time. In the curriculum for business administration HEC has introduced courses on behavioral psychology such as Organizational Behavior, Effect of Culture on Managers Decisions (MBA elective) and Consumer behavior, however at $\mathrm{M}$ Phil there is no strict standard course dealing with applied psychology. Most of the courses have been offered at graduate and undergraduate level, and close to none at the research level (M Phil).

\section{LITERATURE REVIEW}

The literature review explains the current role of managers in an organization. It establishes the link between curricular input of the academia in Management School and its consequent output in the industrial milieu. The literature review further establishes the synergetic correlation the scholarship of Applied Psychology can provide the School of Management Sciences so the managers it produces understand the employees as embodiment so finer characteristics. Such an understanding can result in better organizational output.

\section{A. Management and Managers}

Anderson (2012, p.2) [3] defines Management Sciences as a discipline that assist people in improving their decision making skills. Decision making is the most important process in an organization and at center of this exertion is the manager. It is a manager's role to use the resources and the time opportunely and judiciously in a fiercely competitive world to help the organization sail through. Augier and Teece (2009) [4] say that an organization requires a well- coordinated hand that ensures an exhibition of entrepreneurial and professional expertise. They therefore present the role of managers as individuals who need to be dynamic in their decision making in terms of strategy formulation and implementation, developing and enhancing organization's capacity to sense and seize prospects and recognition, building and allocation of skillful human resource. Helfat et.al (2007) [5] believe that organizations need to "run smart" by managers. Managers are therefore seen in the light of being leaders.

Smircich and Morgan (1982) [6] and Berger and Luckmann (1966) [7] believe leadership is a phenomenon social in nature and dimensions which is defined through communal interaction. Smircich and Morgan (1982) [6] further state that a leader is recognized by his/her ability to rise up to the situation above others and provide others with a sense of organization, and even when they feel and know that things can go extremely wrong corporate leaders (managers) can provide the people within the organization a sense of direction. Pondy, Frost, Morgon and Dandrige (1982) [8] and Smircich (1982) [6] state that leaders need to orient individuals to achieve desirable goals. They can achieve this objective through the use of rituals, language, and stories. They can use symbols, and drama even myths and gestures to execute and control. Kinder and Robertson (1994) [9] expatiated the character traits in managerial leadership saying that successful managers possess a diverse skill set some of which includes interpersonal sensitivity, ability to make decision, ability to analyze and judge the situation, communication, and persuasiveness. Here managers have been identified in terms of personality traits.

\section{B. Applied Psychology and Managers}

Psychology is generally defined as a branch of science which studies humans in terms of their mental and cognitive development and applied Psychology is the application of psychological principals in natural settings which is why industrial and organization psychology is predominantly an applied science since it aims to answer questions like how does one create an environment where employees and employers can make effective decision etc. (Smither, 1994) [1]. Continuing from the previous section this trait identification mentioned in point 1 under the heading of Management and Managers is part of what psychologists call personality psychology (Liebert \& Spiegler, 1990) [10]. Liebert \& Spiegler (1990) [10] define personality as "the unique dynamic organization of characteristic of a particular person, physical and psychological which influences behavior and responses to the social and psychical environment."

Therefore it is not only important for managers to be able to have awareness and skill of personality assessment but it is also important for those who hire managers to be able judge 
whether the hired manager will be able to adapt to the environment or not.

Sociability, emotionality and activity level (Liebert \& Spiegler, 1990) [10] are the three temperament states which can set managers apart as either exceptional or otherwise. Managers also need to understand how individuals behave in isolation and how they would behave in teams in terms of seniority, gender, race, environmental interaction, personal sociability, emotional response, and problem solving (Balderson and Boderick, 1996) [11]. In order for managers to understand the depth of the work environment they are professionally tied to they need to understand the concept of managerial psychology which constitutes leadership and followership, stakeholders value in terms of perception, discernment, satisfaction and productivity (Furnham, 2007). Furnham (2007) [12] calls managerial psychology a "hybrid discipline" which draws from "cognitive and social, personality and physiological psychologists for their ideas, methods and explanations."

Smither (1994) [1] believes that managers have been using principals of psychology on job. However this is an outcome of practice hands-on rather than training. Extensive research has been conducted on how psychology is being used in managerial sciences to improve organizational output. Merkle-Davies, Brennan and McLeay (2010) [13] have worked on how managers and organizations can work on 'impression management' which is a branch of social psychology. Impression management emanates from managers ability to make sense of the situations, anticipation of feedback, effectiveness of the anticipation analysis on decision making and using managerial sense making in retrospective contexts. Salter and High House (2009) [14] have shown the need for managers to show situation judgement and common sense. They include this component as an important part of industrial and organizational psychology and the use of Situational Judgement Tests (SJTs) can show who in the management has the ability to show sharpness and quickness of mind to make timely judgements and consequently execute appropriate plans. Wang and Satow (1994) [15] have produced useful research literature on managers' socio-psychological orientation in organizational settings especially in joint ventures. They divide this orientation into two major components. First is the manager's self-responsibility (cognitive component) and second is manager's sense of collectivism (social component). A manager in an organization is the embodiment of these two components and thus his/her decisions are reflective of his/her ability to use this orientation. Self-responsibility shows how confident managers are in exercising control through decision making. Millward et al. (2009) [16] have shown the utility of feedback in psychoanalyzing managers and consequently as a technique for "diagnostic input". Bandura and Lyons (2012) [17] speak at length on the role of managers in organizational behavior in terms of practitioners of psychological principles through training and development of managers for helpful behavior orientation.

Bradberry (2009) [18], Bandura and Lyons (2012) [17] believe that even though people join organizations they leave their bosses. In such a scenario managers play a vital role in boosting employee morale, work based motivation, positive reinforcement through behavioral influences, providing excellence in supervision and opportunities for advancement for employees, organizational commitment and execution of justice or the perception of fairness and prevention of permeation of biases at different tiers within organizations. Weinberg et al., (2010) [19] and Rousseau et at. (2009) [20] have stressed on psychological impact of procedural justice in the well-being of employees (Weinberg et al., 2010, pp. 17) [19]

\section{APPLIED PSYCHOLOGY IN MANAGEMENT SCIENCES: BENEFITS FOR ACADEMIC UNDERSTANDING AND PRACTICE}

Gordon and Howell (1959)[21] had strongly suggested that business schools should be studying and behavioral sciences and psychology as an imperative discipline and even though organizational behavior has been introduced at various levels in business and management schools in American and most countries in the world, in Pakistan however it needs to be paid special attention to. Although, Courses based on psychological principals form part of the curriculum, they are open to choice and may be skirted at M Phil level altogether. Applied curriculum on Psychology illustrating the underpinnings of human behavior in its various manifestations should be made a compulsory course by Higher Education Commission especially at M Phil level where researchers, irrespective of their majors, where required, can incorporate the psychological aspects of empiricism in their study.

The present curriculum it is felt teaches the right know-how to the potential students of academic and research in management how technical skills make efficient controllers. Business and management schools in Pakistan especially are focusing comprehensively on the role of organizations as value maximizing units whereby value is most often defined in financial and economic terms (Donaldson, Davis \& Schoorman, 1997) [22]. The need of the hour is to help students of managerial sciences to understand the role of managers as humans first and then as technicians who use organizational apparatuses efficiently to produce desired results for principals (bosses, CEOs). Studying applied psychology can help students of management understand the psychological underpinnings of a human mind in broader sense to help them draw multi-variant conclusions. At the post graduate level students are required to choose their majors in business administration limited to three options: finance, marketing, and human resource. Though masters in finance are purely bereft of any shade of psychology in its curriculum, marketing and human resource management has incorporated courses dealing with behavior and attitudes in the HEC list of courses.

Human resource management more than marketing applies the psychological principals in its compulsory and elective courses such as organizational behavior, organizational culture, human resource training and development (recruitment and termination, causes and consequences of attitudes and organizational practices and its links with job-turnover rates). 
Marketing on the other hand stresses mostly on consumer behavior (customer satisfaction, customization of products, trends in consumer choices). Only peripheral attention is paid to marketers as subjects of psychology themselves, marketing related stress, consumer stress, psychology behind marketing decisions and marketers and consumers interaction on different platform whereby each can look at each other as subject of psychological analysis and draw conclusions for better selling and purchasing decisions.

Some sub-disciplines of psychology which can prove immensely useful in management schools to teach behavior of managers, employees, organizations, consumers, supervisors, employers, competitions, in short all those human factors that form the fabric of business and management world are cognitive psychology, learning, intelligence and organization, consumer psychology, psychology of personality, industrial-organizational psychology, stress psychology, social psychology and Gestalt psychology. This section stresses on three schools of psychology and their benefits for managers.

\section{1) Psychoanalysis and managerial benefits}

The father of the school of Psychoanalysis is Sigmund Freud, a Viennese neurologist and the author of The Interpretation of Dreams. Freud believed that more than the conscious, it is the unconscious in people which behavioral outcomes in them. He was the one who associated human mind to the iceberg principle which says that the tip is the conscious mind and what lies below the water is the unconscious mind in the humans. It is the unconscious mind which controls them. The unconscious mind is not restricted. It is vast and most certainly not defined clearly. Though for some time psychoanalysis lost popularity for being too vague, now however many psychologists have accepted that many a time people are not sure why they behave, feel, think and act the way they do. Therefore, the unconscious does have a profound impact on people (Erdelyi, 1985) [23]. Psychoanalysis can help managers understand that with people sometimes it is important to go deeper with problem identification than with on surface solutions. This going deeper into problem solving is what Peter M. Senge (1990, 1997) [24] describes as Systems Thinking in his book The Fifth Discipline: The Art \& Practice of the Learning Organization. Senge says "Business and other human endeavors are ...bound by invisible fabric of interrelated actions..." He stresses on probing for deeper meanings by looking at the whole picture rather than taking isolated snapshots of difficulties.

Managers too need to think holistically. Employee behavior is not just the outcome of visible indicators; it could be a result of something not defined enough. Managers therefore need to dig deeper to understand and control employee behavior and attitude. This can in turn help managers develop a foresight through experience but at the same time probing for what has not been experienced before. It can help managers look for potential problems and help them take care of it well before time as well.

\section{2) Behaviorism and managerial benefits}

Behaviorism according to John Watson (1913) [25] is "a purely objective experimental branch of natural science. Its theoretical goal is the prediction and control of behavior." Catania and Harnand (1985) [26] call Behavior as a "fundamental subject matter". They stress on behavior not leading to any indirect study of mind and thinking. Behavior for them is a study itself. Training and development programmes are one way of reinforcing employee behavior in terms of learning and relearning the practical application of skills. Managers who supervise employees can study employee behavior to control problem indicators and prevent them from reinforcement through fair and judicious process of management of mistakes in order to improve employees' sense of attachment to the organization and their personal well-being. Braunstein (1972) [27] has provided a behavioral view of management sciences stating that management scientists need to understand the behaviorist school of thought in order to understand organizational behavior rather than parroting selected theories in trying to understand managerial problems. He believes "sober analysis of behavioral information which can be applied to a variety of management problems is sorely needed." Managers need to become behaviorists to understand the patterns of organizational behavior. Ensure positive and negative reinforcement of behavior as appropriate for better organizational outcomes. Managers need to have a knowhow of employee behavior as individuals and employee behavior in a team. Such a distinction can help them to correlate action and attitude patterns with organizational output.

\section{3) Humanistic psychology and managerial benefits}

American psychologist Abraham Maslow (creator of the pyramidal Hierarchy of Needs) and Carl Rogers were the pioneers of Humanistic movement in psychology. Rogers believed that humans are naturally prone to discover their full potential. This full potential is what Maslow called "Self Actualization". Humanistic psychology emerging as a third force in 1950s and 1960s believed that individuals need to clarify their senses in order to facilitate the process of personal healing. Humanism is often referred to as "anon-judgmental, nondirective approach" to provide help to people (Buhler, Allen \& Vandervoort, 1972) [28]. Managers need to know how to help people working under them acquire their full potential. Managers can directly and indirectly help organization achieve their full potential by driving the teams within the organization's to achieve their individual and collective potential. Activities like these can help lower down the job turnover rate, improve employee performance, change attitudes towards work for the better and reduce work based stress as a result of attitude change.

\section{CONCLUSION}

The study has applied deductive reasoning to establish the links between academia and industry and how applied psychology as a subject can make better managers. The understanding of at least these three schools of psychology and their applied side in the subfields of stress psychology, temperament psychology, consumer psychology, social psychology, industrial and organizational psychology, learning and intelligence and cognitive psychology can prove to be immensely useful for the students of management 
sciences especially at the M Phil level irrespective of their majors. It will help them acquire a more holistic view of postindustrial, new world managerial problems, where managers cannot be just machines producing wealth for their organizations. Managers need to produce an evolved understanding of in-group and out-group contexts, organizations within themselves and in the ecological makeup of competitive world and an empathetic view of machinations of human brain, feelings, motives, values and culture. In a situation like this, the M Phil students of Management Sciences need to study a richer curriculum. Such a curriculum should be imbued with thoroughness of organizations and employees seen in the light of humanistic embodiments as well as apparatuses of organizational output. Consequently, the contributions of these students as graduates are likely to improve the organizational practices and increase the organizational efficacy in task execution.

\section{LIMITATIONS}

The study predominantly focuses of academia and its possible impact on the industry. It is a desk based research. This can limit the understanding of finer nuances of industrial practices.

Due to time constraints limited literature review was conducted. The study can be treated as a pilot to a more thorough research.

If quantitative apparatus is added one can obtain better results. Given the same framework the results can vary contextually.

\section{REFERENCES}

[1] R. D. Smither, The Psychology of Work and Human Performance, vol. 6, 1994.

[2] C. Sam, Higher Education in Transition: Stakeholder Involvement and Challenges for Academic Institutions in Cambodia, 2016.

[3] D. R. Anderson, An Introduction to Management Science: Quantitative Approaches to Decision Making, Cengage Learning, 2012.

[4] M. Augier and D. J. Teece, "Dynamic capabilities and the role of managers in business strategy and economic performance," Organization Science, vol. 20, no. 2, pp. 410-421, 2009.

[5] C. Helfat, S. Finkelstein, W. Mitchell, M. A. Peteraf, H. Singh, D. J. Teece, and S. Winter, Dynamic Capabilities: Understanding Strategic Change in Organizations, Blackwell, Oxford, UK, 2007.

[6] L. Smircich and G. Morgan, "Leadership: The management of meaning," The Journal of Applied Behavioral Science, vol. 18, no. 3, pp. 257-273, 1982.

[7] P. L. Berger and T. T. Luckmann, The Social Construction of Reality, 1966.

[8] L. Pondy, P. Frost, G. Morgan, and T. Dandridge Eds, Organizational Symbolism Greewich, Conn. JAI Press, 1982.
[9] A. Kinder and I. T. Robertson, "Do You have the Personality to be a Leader?: The importance of Personality Dimensions for Successful Managers and Leaders," Leadership and Organization Development Journal, vol. 15, no. 1, pp. 3-12, 1994.

[10] R. M. Liebert and M. D. Spiegler, Personality: Strategies and Issues, California: Brooks, 1990.

[11] S. J. Baldersona and A. J. Broderick, "Behaviour in teams: exploring occupational and gender differences," Journal of Managerial Psychology, vol. 11, no. 5, pp. 33-42, 1996.

[12] A. Furnham, "Managerial psychology: state-of-the-art," Journal of Managerial Psychology, vol. 22, no. 6, pp. 610-621, 2007.

[13] D. M. Merkl-Davies, N. M. Brennan, and S. J McLeay, "Impression management and retrospective sense-making in corporate narratives: a social psychology perspective," Accounting, Auditing \& Accountability Journal, vol. 24, no. 3, pp. 315-344, 2011.

[14] N. P. Salter and S. Highhouse, "Assessing managers' common sense using situational judgment tests," Management Decision, vol. 47, no. 3, pp. 392-398, 2009.

[15] Z. M. Wang and T. Satow, "The effects of structural and organizational factors on socio-psychological orientation in joint ventures," Journal of Managerial Psychology, vol. 9, no. 4, pp. 22-30, 1994.

[16] J. Millward, M. Asumeng, and A. McDowall, "Catch me if you can?" A psychological analysis of managers' feedback seeking," Journal of Managerial Psychology, vol. 25, no. 4, pp. 384-407, 2010.

[17] R. P. Bandura and P. R. Lyons, "Helping managers stimulate employee voluntary, helpful behavior," Industrial and Commercial Training, vol. 44, no. 2, pp. 94-102, 2012.

[18] T. Bradberry, "The cost of seagull management," Industrial and Commercial Training, vol. 41, no. 3, pp. 139-141, 2009.

[19] W. D. M Olvet and G. Hajcak, "Increased error-related brain activity in generalized anxiety disorder," Biological Psychology, vol. 85, no. 3, pp. 472-480, 2010.

[20] C. Rousseau, S. T. Kuile, M Muñoz, L. Nadeau, M. J. Ouimet, L. Kirmayer, and F. Crépeau, "Health care access for refugees and immigrants with precarious status: public health and human right challenges," Can J Public Health, vol. 99, no. 4, pp. 290-292, 2009.

[21] R. A. Gordon and J. E. Howell, "Higher education for business," Journal of Education for Business, vol. 35, no. 3, pp. 115-117, 1959.

[22] J. H. Davis, F. D. Schoorman, and L. Donaldson, "Toward a stewardship theory of management," Academy of Management Review, vol. 22 , no. 1 , pp. $20-47,1997$

[23] M. H. Erdelyi and M. H. Erdelyi, Psychoanalysis: Freud's Cognitive Psychology, 1985

[24] P. M. Senge, The Fifth Discipline, Measuring Business Excellence, vol. 1, no. 3, pp. 46-51, 1997.

[25] J. B. Watson, Psychology as the Behaviorist Views it, Psychological Review Company, 1913.

[26] A.C. Catania and S. Harnad (Eds), The Selection of Behavior: The Operant Behaviorism of B.F. Skinner: Comments and Consequences, Cambridge University Press, Cambridge, 1988.

[27] D. N. Braunstein, Behavioral Science-Management Science: A Behavioral View, Interfaces, vol. 2, no. 3, pp. 25-28, 1972.

[28] C. Bühler, M., Allen, and M. Vandervoort, Introduction to Humanistic Psychology, Monterey, California: Brooks/Cole Publishing Company, 1972.

T. Shakoor is an assistant professor in the Department of Humanities and Social Sciences at Bahria University, Islamabad Campus, Islamabad, Pakistan. Ms. Shakoor has an M Phil in Management Sciences from Bahria University. She has an MBA degree from Bahra University and MA English Literature from Punjab University. Ms. Shakoor has been teaching English in the department of Humanities and Social Sciences for the last nine years. 